\title{
PELATIHAN PENGEMBANGAN MEDIA INTERAKTIF BERBASISKAN KONTEKSTUAL PADA GURU-GURU SMP LUBUK SIKAPING
}

\author{
Hufri $^{1}$, Letmi Dwiridal ${ }^{2}$, Silvi Yulia Sari ${ }^{3}$ \\ ${ }^{1,3}$ Program Studi Pendidikan Fisika, Fakultas MIPA, Universitas Negeri Padang, \\ Jalan Prof. Dr. Hamka Air Tawar Padang \\ ${ }^{2}$ Program Studi Fisika, Fakultas MIPA, Universitas Negeri Padang, \\ Jalan Prof. Dr. Hamka Air Tawar Padang \\ 1e-mail: hufri_fis@fmipa.unp.ac.id
}

\begin{abstract}
Abstrak
Kegiatan PKM ini bertujuan untuk meningkatkan kompetensi guru-guru SMP Lubuk Sikaping dalam mengembangkan media interaktif berbasis kontekstual. Metode yang digunakan terdiri dari beberapa tahap yaitu tahap observasi, persiapan, pelaksanaan, monitoring. Hasil analisis data dari pretest dan postest, disimpulkan bahwa kegiatan PKM ini telah dapat meningkatkan kemampuan guru-guru IPA SMP Lubuk Sikaping dalam mengembangkan media pembelajaran interaktif, sehingga dapat meningkatkan kualitas pembelajaran. Berdasarkan angket yang diberikan pada akhir kegiatan pelatihan, diperoleh hasil bahwa peserta menyatakan kegiatan ini sangat bermanfaat dan berkaitan dengan pembelajaran di sekolah.
\end{abstract}

Kata kunci: media interaktif, pembelajaran, kontekstual

\begin{abstract}
This PKM activity aims to improve the competencies of Lubuk Sikaping junior school teachers in developing contextual-based interactive media.The method used consists of several stages, namely the stage of observation, preparation, implementation, monitoring. The results of data analysis from the pretest and posttest, it was concluded that this PKM activity had been able to improve the abilities of Lubuk Sikaping junior school science teachers in developing interactive learning media, so as to improve the quality of learning. Based on the questionnaire given at the end of the training activity, the results were obtained that the participants stated this activity was very useful and related to learning in school.
\end{abstract}

Keywords: interactive media, learning, contextual

\section{PENDAHULUAN}

Permasalahan pendidikan yang dihadapi sekolah pada umumnya adalah masih rendahnya hasil belajar yang diperoleh oleh siswa, kondisi ini juga terjadi pada sekolah di kabupaten Pasaman. Hal ini dapat dilihat dari hasil peringkat UN tahun 2016 untuk tingkat SMP berada pada peringkat 15 dari 19 kota/kabupaten yang ada di Sumatera Barat (Kemdikbud, 2017).

Berdasarkan pengamatan dan diskusi yang dilakukan dengan beberapa guru dan kepala sekolah dalam pembelajaran umumnya guru belum mengembangkan bahan ajar sendiri, dengan mengkaitkan materi tersebut dengan kondisi di sekitar 
siswa. Selanjutnya dalam pembelajaran media yang digunakan belum mengakomodasi kondisi dan fakta yang ada disekitar siswa, sehingga pembelajaran yang dilakukan tidak maksimal dalam melibatkan siswa secara aktif.

Pembelajaran adalah usaha sadar seorang guru untuk membelajarkan siswanya dengan mengarahkan interaksi antara siswa dan sumber belajar dalam mencapai tujuan yang diharapkan. Proses pembelajaran terjadi jika adanya interaksi antara 3 komponen yaitu pendidik, peserta didik, dan sumber belajar (Trianto,2014). Pembelajaran memerlukan kondisi atau suasana yang dapat membuat belajar lebih mudah, sederhana, bermakna dan menyenangkan agar siswa mudah menerima ide, gagasan, mudah memahami permasalahan dan pengetahuan serta dapat mengkonstruksi sendiri pengetahuan barunya secara aktif, kreatif dan produktif. Agar usaha tersebut dapat tercapai maka salah satu pendekatan yang dapat digunakan adalah pembelajaran kontekstual. Pendekatan kontekstual merupakan proses belajar yang membantu guru mengaitkan antara meteri yang diajarkannya dengan situasi dunia nyata siswa dan mendorong siswa membuat hubungan antara pengetahuan yang dimilikinya dengan penerapannya dalam kehidupan sehari-hari. Hasil atau prestasi belajar siswa tidak hanya dilihat dari tampilan kuantitatif, melainkan juga dilihat dari sisi kualitas penguasaan dan aplikasinya dalam kehidupan yang nyata. Jadi pembelajaran kontekstual merupakan pembelajaran yang mengaitkan materi yang dipelajari dengan kehidupan nyata, dan memotivasi siswa untuk mengaitkan pengetahuan yang didapatnya dengan kehidupan mereka sehari-hari (Masnur, 2007).

Pembelajaran kontekstual akan dapat meningkatkan peran siswa, dalam kegiatan belajarnya. Pada pembelajaran kontekstual dapat memotivasi siswa, untuk menghubungkan pengetahuan yang mereka peroleh dengan kehidupan sehari-hari. Selanjutnya diharapkan mereka dapat menerapkan pengetahuan tersebut, untuk memecahkan masalah pribadi maupun masalah di lingkungan sekitarnya. Sehingga pembelajaran yang mereka lakukan lebih bermakna dan sesuai dengan kebutuhan mereka sebagai individu dan sebagai anggota 
masyarakat. Penerapan pembelajaran kontekstual, juga telah dapat meningkatkan hasil belajar siswa (Hufri, 2017).

Pembelajaran kontekstual dagar dapat diterapkan secara optimal, maka guru dapat menggunakan media dalam pembelajaranya. Proses kegiatan pembelajaran harus diubah dari pola pembelajaran satu arah (interaksi guru-peserta didik) menjadi pembelajaran interaktif (interaktif guru-peserta didik-masyarakatlingkungan alam, sumber/media lainnya), pola pembelajaran pasif menjadi pembelajaran aktif-mencari (pembelajaran siswa aktif mencari semakin diperkuat dengan model pembelajaran dan pendekatan sains) dan pola pembelajaran alat tunggal menjadi pembelajaran berbasis alat multimedia.

Media pembelajaran merupakan salah satu alternatif yang dapat digunakan untuk membantu siswa dalam mengatasi permasalahan pembelajaran tersebut. Jenis media pembelajaran yang bisa digunakan guru dalam proses pembelajaran tersebut antara lain adalah media interaktif. Media interaktif ini dapat mengaktifkan beberapa indera siswa secara bersamaan, yaitu penglihatan, pendengaran, dan sentuhan (Yusuf, 2014). Media pembelajaran berfungsi untuk memperjelas penyajian materi agar tidak membosankan dan dapat dipahami dengan mudah, media juga dapat mengatasi keterbatasan daya indera, ruang dan waktu agar kegiatan belajar lebih kondusif. Penggunaan media pembelajaran yang menarik juga akan dapat meningkatkan semangat belajar siswa. Media pembelajaran harus dapat membantu siswa dan disusun dengan mempertimbangkan keterampilan dan pengetahuan yang dimiliki siswa. Serta disesuaikan dengan bahan belajar yang akan disampaikan oleh guru. Sesuai dengan perkembangan teknologi maka sekarang digunakan berbagai jenis/bentuk media secara berurutan maupun simultan dalam menyampaikan suatu informasi yang biasa disebut dengan multimedia pembelajaran.

Pembelajaran berbasis multimedia akan lebih menarik, tidak monoton, dan memudahkan penyampaian. Peserta didik dapat mempelajari materi pelajaran secara mandiri dengan komputer yang dilengkapi dengan program yang dibutuhkan. Multimedia pembelajaran interaktif dibuat berdasarkan kreatifitas guru dalam membelajarkan materi pembelajaran dengan memanfaatkan media 
yang ada (Hufri \& Amir, 2018). Pengembangan multimedia berbasikan kontestual ini juga telah dapat meningkatkan kemampuan guru dalam pembelajarannya (Sari, Hufri, \& Dewi, 2018).

Selanjutnya sesuai dengan pendekatan saintifik siswa diharapkan mampu berperan aktif dalam proses pembelajaran dengan mengamati, menanya, mencoba, manalar, lalu mengkomunikasikan yang telah didapatkan dengan menanamkan karakter pada setiap siswa sehingga tercipta siswa yang kreatif dan inovatif (Kemdikbud, 2013). Jadi dalam pembelajaran, peserta didik didorong untuk belajar melalui keterlibatan aktif dengan keterampilan-keterampilan, konsepkonsep, dan prinsip-prinsip. Guru mendorong peserta didik untuk mendapatkan pengalaman dengan melakukan kegiatan yang memungkinkan mereka menemukan konsep dan prinsip-prinsip untuk diri mereka sendiri. Dengan kata lain, pembelajaran terjadi apabila peserta didik terlibat secara aktif dalam menggunakan proses mentalnya agar mereka memperoleh pengalaman, sehingga memungkinkan mereka untuk menemukan konsep atau prinsip tersebut. Jadi pembelajaran kontekstual dengan menggunakan multimedia interaktif akan dapat membatu guru dalam meningkatkan keterlibatan siswa dalam pembelajarannya, sehingga proses pembelajaran saintifik seperti yang di tuntut dalam kurikulum dapat diwujudkan.

Jadi pembelajaran merupakan suatu proses kompleks yang terjadi pada diri setiap orang sepanjang hidupnya. Belajar bukan hanya sekedar aktivitas yang sedang terjadi pada diri individu, akan tetapi terjadi atas usaha individu sendiri dengan cara mengolah informasi yang ada dan menerapkanya. Hal ini sesuai dengan tuntutan kurikulum 2013 bahwa pembelajaran ditujukan untuk mengembangkan potensi peserta didik agar memiliki kemampuan hidup sebagai pribadi dan warga negara yang beriman, produktif, kreatif, inovatif, dan afektif, serta mampu berkontribusi pada kehidupan masyarakat, berbangsa, bernegara, dan peradaban dunia. Untuk dapat melaksanakan pembelajaran sesuai dengan tuntutan kurikulum, maka diperlukan kemampuan dari guru untuk menciptakan kondisi agar dapat terjadi pembelajaran tersebut. 
Permasalahan yang dihadapi guru-guru SMP pada MGMP rayon 2 Kabupaten Pasaman di Lubuk Sikaping yaitu belum dapat mengembangkan multimedia interaktif, media yang digunakan masih terbatas pada media tunggal seperti papan tulis, kalaupun ada menggunakan media tetapi tidak dirancang sendiri yang bersumber dari lingkungan siswa. Hal ini disebabkan karena kompetensi guru-guru dalam mengembangkan media pembelajaran masih rendah, sebagian besar guru masih merasa kesulitan untuk mengembangkan media pembelajaran yang akan digunakan dalam pembelajarannya. Terutama yang dapat membantu siswa mengaitkan antara materi yang diajarkan dengan situasi dunia nyata dan mendorong siswa membuat hubungan antara pengetahuan yang dimilikinya dengan penerapan dalam kehidupan mereka sehari-hari.

Secara khusus berdasarkan diskusi dengan kelompok Mitra serta pengamatan langsung di lapangan, tim dapat mengidentifikasi permasalahan dalam pembelajaran yang dihadapi oleh mitra seperti terdapat dalam Tabel 1.

Tabel 1. Masalah-masalah yang dihadapi oleh mitra

\begin{tabular}{cl}
\hline Aspek & \multicolumn{1}{c}{ Masalah yang dihadapi } \\
\hline Siswa & Rendahnya hasil belajar siswa \\
\hline 1. Kurangnya keterampilan guru dalam menggunakan \\
fasilitas teknologi informasi untuk menunjang \\
kurikulum 2013 \\
2. Kompetensi guru-guru dalam merancang dan \\
mengembangkan media interaktif berbasiskan \\
kontekstual masih rendah, walaupun kenyataannya \\
banyak jenis dan ragam fenomena alam di \\
sekitarnya yang dapat dikembangkan dan \\
dimanfaatkan untuk menunjang pembelajaran. \\
\hline Pembelajaran yang dilakukan belum berpusat pada \\
Siswa dan bahan ajar yang digunakan masih \\
terbatas pada terbitan penerbit nasional, sehingga \\
belum memasukan kondisi lingkungan siswa dalam \\
materinya belajar di
\end{tabular}

Solusi yang ditawarkan adalah peningkatan kualitas pembelajaran melalui peningkatan kompetensi guru-guru SMP Lubuk Sikaping dalam mengembangkan media interaktif berbasis kontekstual. Berdasarkan identifikasi permasalahan yang 
terjadi pada mitra dan solusi yang berikan, maka dibutuhkan beberapa bidang keahlian yaitu pendidikan fisika untuk pendampingan dalam mengembangan media interaktif, pembelajaran kontekstual dan keahlian fisika untuk menganalisis kecocokan fenomena pada lingkungan dengan konsep IPA.

\section{METODE}

Metode yang digunakan untuk melaksanakan kegiatan pelatihan pengembangan media interaktif berbasiskan kontekstual, dilakukan melalui lima tahap. Tahap-tahap kegiatan tersebut adalah orientasi dan diskusi, tahapan persiapan pelaksanaan, tahapan pelaksanaan, tahapan monitoring dan evaluasi serta taap analisis data. Selanjutnya secara rinci tahapan kegiatan, jenis kegiatan tempat pelaksanaan kegiatan dapat dilihat pada Tabel 2.

Tabel 2. Tahap-tahap kegiatan dan tempat pelaksanaannya

\begin{tabular}{|c|c|c|}
\hline $\begin{array}{l}\text { Tahapan } \\
\text { Kegiatan }\end{array}$ & Jenis Kegiatan & Tempat \\
\hline $\begin{array}{l}\text { Orientasi dan } \\
\text { diskusi }\end{array}$ & $\begin{array}{l}\text { Mengidentifikasi permasalahan yang ada pada } \\
\text { mitra, dan teknik yang dilakukan untuk } \\
\text { mengatasi masalah tersebut. Disamping itu, } \\
\text { juga disusun rencana dan jadwal kegiatan PKM } \\
\text { bersama mitra }\end{array}$ & $\begin{array}{l}\text { Tempat } \\
\text { Mitra }\end{array}$ \\
\hline $\begin{array}{l}\text { Persiapan } \\
\text { Pelaksanaan }\end{array}$ & $\begin{array}{l}\text { Mempersiapkan alat dan bahan pendukung } \\
\text { untuk pelaksanaan pelatihan pengembangan } \\
\text { media interaktif berbasiskan kontekstual. } \\
\text { Menyiapkan instrumen yang digunakan, untuk } \\
\text { pengumpul data yang akan digunakan dalam } \\
\text { kegiatan }\end{array}$ & $\begin{array}{l}\text { Laboratorium } \\
\text { PBM Fisika } \\
\text { UNP }\end{array}$ \\
\hline \multirow[b]{2}{*}{$\begin{array}{l}\text { Pelaksanaan } \\
\text { pelatihan }\end{array}$} & $\begin{array}{l}\text { Pemberian wawasan dan pengetahuan tentang } \\
\text { pembelajaran kontekstul, media pembelajaran } \\
\text { dan cara merancang media interaktif. }\end{array}$ & $\begin{array}{l}\text { Tempat } \\
\text { Mitra }\end{array}$ \\
\hline & $\begin{array}{l}\text { Pendampingan dalam mengembangkan } \\
\text { multimedia pembelajaran, sehingga dihasilkan } \\
\text { multimedia interaktif yang dapat digunakan } \\
\text { dalam pembelajaran }\end{array}$ & $\begin{array}{l}\text { Tempat } \\
\text { Mitra }\end{array}$ \\
\hline $\begin{array}{l}\text { Monitoring } \\
\text { dan evaluasi }\end{array}$ & $\begin{array}{l}\text { Melakukan monitoring dan evaluasi atas } \\
\text { pelaksanaan PKM yang telah dilakukan }\end{array}$ & $\begin{array}{l}\text { Tempat } \\
\text { Mitra }\end{array}$ \\
\hline Analisis & Untuk melihat peningkatan kompetensi guru & Laboratorium \\
\hline
\end{tabular}




\begin{tabular}{lll}
\hline $\begin{array}{c}\text { Tahapan } \\
\text { Kegiatan }\end{array}$ & \multicolumn{1}{c}{ Jenis Kegiatan } & \multicolumn{1}{c}{ Tempat } \\
\hline data & $\begin{array}{l}\text { dalam pengembangan media interaktif } \\
\text { berbasiskan kontekstual dan tingkat respon } \\
\text { mitra terhadap kegiatan yang dilakukan }\end{array}$ & PBM Fisika \\
& UNP \\
\hline
\end{tabular}

Kegiatan PKM ini dilaksanakan di SMPN 1 Lubuk Sikaping, yang diikuti oleh guru-guru IPA di MGMP rayon 2 Kabupaten Pasaman di Lubuk Sikaping, dengan jumlah peserta sebanyak 21 orang.

\section{HASIL DAN PEMBAHASAN}

Sesuai dengan tujuan kegiatan PKM ini, yaitu meningkatkan kompetensi guru-guru SMP Lubuk Sikaping dalam mengembangkan media interaktif berbasis kontekstual. Kegiatan yang dilakukan pertama adalah memberikan pengetahuan secara teoritis tentang pengembangan media pembelajaran interaktif berbasikan kontekstual, dengan menggunakan fakta yang dekat dengan kehidupan sehari-hari siswa sehingga dapat memfasilitasi siswa dalam pembelajarannya. Ke dua melakukan diskusi dan pembimbingan pengembangan media pembelajaran interaktif berbasikan kontekstual. Secara lebih rinci, kegiatan yang dilakukan, adalah.

Pada tahap orientasi dan diskusi dilakukan di tempat mitra yaitu di SMPN 1 lubuk Sikaping, yang diikuti oleh guru-guru IPA MGMP rayon 2 Kabupaten Pasaman. Pada diskusi ini diperoleh prioritas masalah yang akan dicarikan solusinya, kesepakatan tentang teknis PKM yang dilakukan, dan jadwal kegiatan. Kegiatan pelatihan diawali dengan pretest, dilanjutkan dengan pemberian pengetahuan tentang pembelajaran kontekstual, media interaktif dan pendampingan pengembangan media interaktif berbasiskan kontekstual dan diakhiri dengan pemberian posttest dan pengisian angket pelaksanaan kegiatan PKM.

Pada tahap persiapan pelaksanaan, dilakukan kegiatan mempersiapkan alat dan bahan pendukung untuk pelaksanaan pelatihan pengembangan media interaktif berbasiskan kontekstual. Pada tahap ini dihasilkan peralatan yang dibutuhkan, instrumen yang akan digunakan untuk pengumpul data. Instrument 
tersebut meliputi instrument pretest dan posttetst serta angket pelaksanaan kegiatan PKM

Pada kegiatan pelaksanaan diawali dengan memberikan pretest dan dilanjutkan dengan pemberian wawasan tentang pembelajaran kontekstual dan pengembangan media interaktif. Dalam pelatihan ini selalu diikuti dengan diskusi antara peserta pelatihan dengan nara sumber dalam hal ini adalah Tim PKM. Berikut adalah pelaksanaan kegiatan.
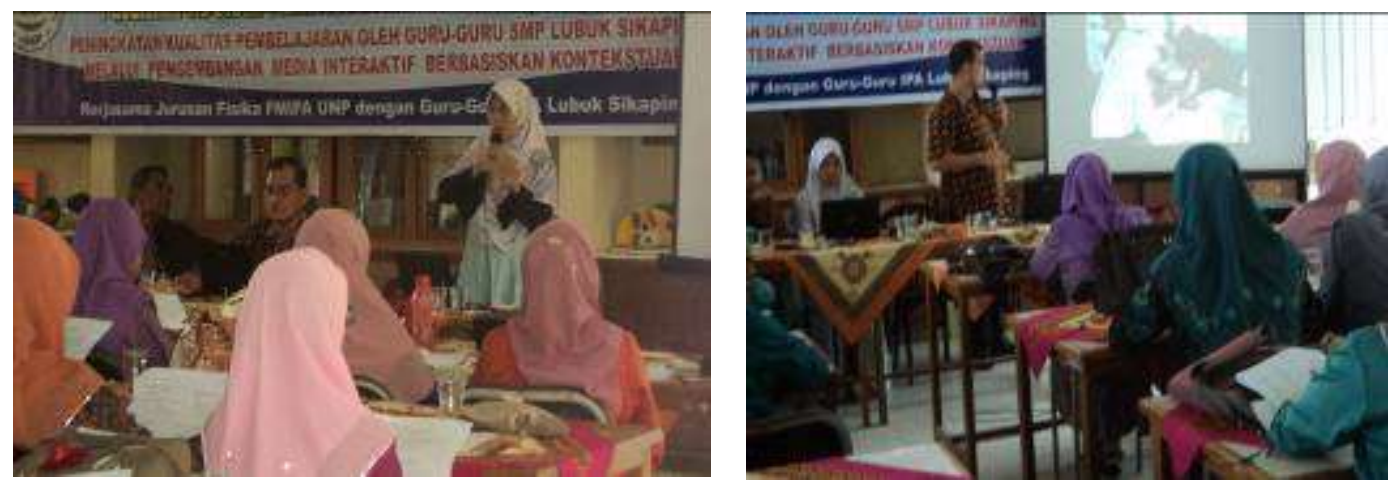

Gambar 1. TIM PKM sedang memberikan materi pelatihan kepada GuruGuru SMPN Pasaman.
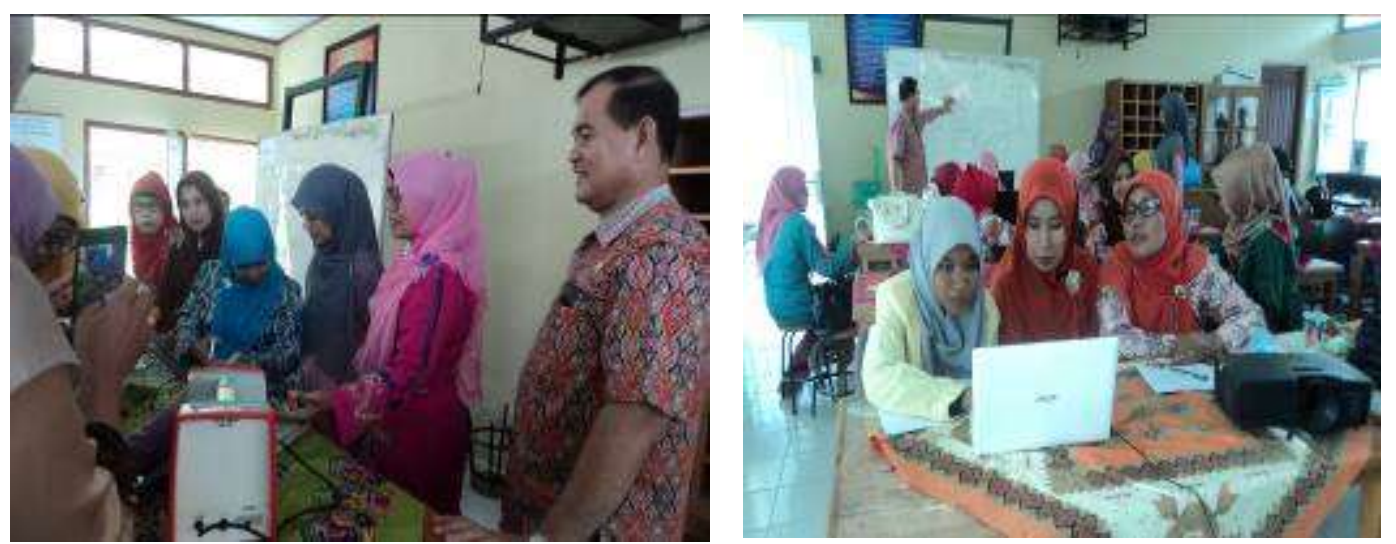

Gambar 2. Guru-Guru serius dalam merancang media interaktif dengan bimbingan TIM PKM

Pada pertemuan-pertemuan selanjutnya dilakukan pendampingan pengembangan media interaktif. Pada tahap pelaksanaan ini juga diperoleh data dari hasil pretest dan posttest, yang mengukur kemampauan peserta PKM tentang pembelajaran kontekstual, media interaktif dan kemampuan dalam merancang media interaktif berbasiskan kontekstual. Pada Tabel 3, menunjukkan bahwa 
terdapat peningkatan kompetensi guru-guru dalam mengembangkan media pembelajaran interaktif berbasis kontekstual.

Tabel 3. Nilai Pre-test, Postest Dan Gain

\begin{tabular}{cccc}
\hline No & Pre-test & Posttest & Gain \\
\hline 1 & 56.7 & 73.3 & 16.7 \\
\hline 2 & 33.3 & 60.0 & 26.7 \\
\hline 3 & 40.0 & 56.7 & 16.7 \\
\hline 4 & 40.0 & 60.0 & 20.0 \\
\hline 5 & 40.0 & 63.3 & 23.3 \\
\hline 6 & 43.3 & 53.3 & 10.0 \\
\hline 7 & 43.3 & 80.0 & 36.7 \\
\hline 8 & 43.3 & 60.0 & 16.7 \\
\hline 9 & 46.7 & 63.3 & 16.7 \\
\hline 10 & 46.7 & 63.3 & 16.7 \\
\hline 11 & 46.7 & 53.3 & 6.7 \\
\hline 12 & 50.0 & 60.0 & 10.0 \\
\hline 13 & 50.0 & 63.3 & 13.3 \\
\hline 14 & 50.0 & 60.0 & 10.0 \\
\hline 15 & 50.0 & 60.0 & 10.0 \\
\hline 16 & 53.3 & 70.0 & 16.7 \\
\hline 17 & 56.7 & 63.3 & 6.7 \\
\hline 18 & 60.0 & 70.0 & 10.0 \\
\hline 19 & 63.3 & 63.3 & 0.0 \\
\hline 20 & 53.3 & 56.7 & 6.7 \\
\hline 21 & 40.0 & 46.7 &
\end{tabular}

Pada tahap monitoring dan evaluasi dilakukan monitoring dari hasil pengembangan media interaktif yang dilakukan guru-guru, dan dilanjutan dengan diskusi tentang kendala yang dihadapi dalam mengembangan media interaktif tersebut. Secara umum guru- guru sudah dapat mengembangkan media interaktif walaupun ada beberapa guru yang masih mempunyai kendala dalam menghubungkan konsep-konsep dalam materi pembelajaran dengan kondisi disekitar siswa. Dengan tahapan ini kendala tersebut dapat diatasi melalui diskusi dengan tim PKM dan guru-guru yang lain.

Pada tahap analisis data, dilakukan analisis terhadap data dari intrumen yang digunakan. Berdasarkan hasil pre-test dan posttest yang diberikan kepada guru- 
guru, data yang diperoleh dianalisis menggunakan SPSS 20, diperoleh deskripsi dari kedua data seperti pada Tabel 4.

Tabel 4. Descriptive Statistics

\begin{tabular}{lccccc}
\hline & N & Minimum & Maximum & Mean & Std. Deviation \\
\hline Pre-test & 21 & 33.30 & 63.30 & 47.93 & 7.56 \\
Posttest & 21 & 46.70 & 80.00 & 61.89 & 7.26 \\
\hline
\end{tabular}

Berdasarkan Tabel 4. dapat dilihat bahwa nilai pretest rata-rata adalah 47.93 dengan nilai minimum adalah 33.30 dan nilai maksimum 63.30. Untuk nilai posttest rata-rata adalah 61.895 dengan nilai minimum adalah 46.7 dan nilai maksimum 80.0. Jadi nilai rata-rata, postest lebih tinggi dibandingkan dengan nilai pretest. Hasil normalitas data seperti pada Tabel 5.

Tabel 5. Hasil Uji Normalitas Data

\begin{tabular}{cccc}
\hline & \multicolumn{3}{c}{ Shapiro-Wilk } \\
\cline { 2 - 4 } & Statistic & df & Sig. \\
\hline Pre-test & 0.973 & 21 & 0.793 \\
Posttest & 0.939 & 21 & 0.204 \\
\hline
\end{tabular}

Berdasarkan hasil analisis pada Tabel 5 diperoleh hasil pretest dengan signifikasi $0.793>0.05$ dan postest dengan signifikansi $0.204>0.05$. Sehingga hasil pre-test dan posttets keduanya berdistribusi normal. Selanjutnya untuk melihat perbedaan dari hasil pretes terhadap postes dilakukan dilakukan uji $\mathrm{t}$ berpasangan. Hasil analisis dapat dilihat pada Tabel 6.

Tabel 6. Paired Samples Test

\begin{tabular}{lccc}
\hline & t & df & Sig. (2-tailed) \\
\hline Pair 1 Pre-test - Posttest & -7.667 & 20 & 0.000 \\
\hline
\end{tabular}

Dari Tabel 6. dapat dilihat signifikansinya $0.000<0.05$, Jadi dapat diambil kesimpulan bahwa terdapat perbedaan antara hasil pre-test dengan posttest. Dimana nilai rata-rata posttest lebih tinggi dari nilai rata-rata pre-test, ini menunjukkan bahwa terdapat peningkatan kompetensi guru-guru dalam mengembangkan media pembelajaran interaktif berbasiskan kontekstual. 
Berdasarkan hasil angket tentang respon peserta terhadap kegiatan PKM, semua peserta menyatakan kegiatan pelatihan ini sangat bermanfaat bagi guruguru dalam meningkatkan kualitas pembelajarannya.

\section{SIMPULAN}

Sesuai dengan hasil yang diperoleh dan pembahasan yang dilakukan dapat ditarik kesimpulan yaitu kegiatan pelatihan yang dilakukan telah dapat meningkatkan kemampuan guru-guru SMP Lubuk Sikaping dalam mengembangkan media pembelajaran interaktif, sehingga dapat meningkatkan kualitas pembelajaran yang dilakukan. Berdasarkan respon peserta bahwa semua peserta menyatakan kegiatan PKM sangat bermanfaat dan dapat membantu guruguru di MGMP rayon 2 Kabupaten Pasaman dalam mengembangan media pembelajaran dengan mengaitkan konsep-konsep yang dipelajari dengan kehidupan sehari-hari siswa. Sehingga kegiatan PKM ini, dapat meningkatkan kualitas pembelajaran.

\section{UCAPAN TERIMA KASIH}

Terima kasih kepada Rektor UNP dan Ketua LP2M UNP yang telah telah mendanai kegiatan PKM ini melalui dana PNBP.

\section{DAFTAR PUSTAKA}

Puspendik.Kemdikbud. (2017). Laporan hasil UN, (Online),(https://hasilun.puspendik.kemdikbud.go.id, diakses 2 Februari 2018).

Al-Tabany, Trianto. (2014). Mendesain model pembelajaran inovatif, progresif, dan kontekstual. Jakarta : Prenadamedia Group.

Muslich, Masnur. (2007). KTSP pembelajaran berbasis ranah dan contextual. Jakarta: PT Bumi Aksara

Hufri. (2017). Pengembangan bahan ajar fisika berbasiskan kontekstual pada pembelajaran quided inquiry untuk kelas xi SMA/MA, Prosiding Semirata 2017 Bidang MIPA BKS-PTN Wilayah Barat 2. Universitas Jambi, hal. 1312-1321.

Elmande, Yusuf. (2014). Modul komunikasi multimedia. Jakarta: Universitas Mercu Buana. 
Hufri \& Harman Amir. (2018). Peningkatan kompetensi guru-guru SMP Solok selatan melalui pelatihan pengembangan media pembelajaran berbasis kontekstual dengan pendekatan saintifik. Jurnal Pelita Eksakta 1, 1, 37-42.

Sari Silvi Yulia, Hufri, Wahyuni Satria Dewi. (2018). Pelatihan pengembangan multimedia berbasiskan kontekstual untuk pembelajaran inquiry bagi guruguru SMPN 19 dan SMPN 34 Kabupaten Solok Selatan. Jurnal Pelita Eksakta 1, 2, 102-107.

Kemdikbud. (2013). Permendikbud No. 70 tahun 2013 kerangka dasar dan struktur kurikulum. Jakarta: Kementerian Pendidikan dan Kebudayaan. 